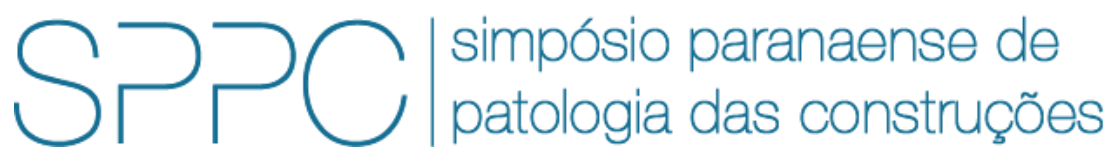

ISSN 2526-7248 artigo 2SPPC1019, pp. 224-236, 2017

\title{
Efeito do grau de hidratação e de saturação do concreto nas leituras de resistividade elétrica
}

\author{
Isaac Aguiar Oliveira ${ }^{1}$, Fernanda Gadler ${ }^{2}$, Analiet Calvo Valdés ${ }^{3}$ e Marcelo Henrique Farias de \\ Medeiros $^{4}$ \\ ${ }_{1}^{1}$ Mestrando do Programa de Pós-Graduação em Engenharia e Construção Civil, UFPR, \\ zacaguiar@gmail.com \\ ${ }^{2}$ Mestranda do Programa de Pós-Graduação em Engenharia e Construção Civil, UFPR, \\ fernandagadler@gmail.com \\ ${ }^{3}$ Mestranda do Programa de Pós-Graduação em Engenharia e Construção Civil, UFPR, \\ analietcv@yahoo.es \\ ${ }^{4}$ Doutor, Universidade Federal do Paraná, medeiros.ufpr@gmail.com
}

Resumo: As estruturas de concreto, por meio da interação que possuem com o meio ambiente, estão submetidas a diversos tipos de agentes que ocasionam degradação. Um dos principais parâmetros utilizados para o monitoramento de estruturas é a resistividade elétrica. Este parâmetro sofre influência de diversos fatores como, por exemplo, grau de saturação, grau de hidratação e composição química do material. Este trabalho estuda o efeito da variação de tais fatores na resistividade, em três dosagens de concreto simples, sendo um o traço de referência (sem adição), e os outros dois com adição, o primeiro com cinza volante e o segundo com sílica de casca de arroz. Os resultados do trabalho mostram que quanto maior o grau de hidratação maior a resistividade do material independentemente do grau de saturação e tipo de adição. Neste contexto, quanto maior a resistência, a resistividade também é mais elevada. Ainda, os dois traços com adições apresentaram maior resistividade do que o traço de referência, com valores bastante elevados no traço com sílica de casca de arroz. Deste modo, é possível concluir que quanto mais ativa seja a adição incorporada, maior serão os valores de resistividade e proteção da peça de concreto.

Palavras-chave: resistividade elétrica, absorção, resistência, cinza volante, sílica de casca de arroz.

Abstract: Concrete structures, through interaction with the environment, are exposed to many types of agents, which cause degradation. One of the main parameters used for the monitoring of structures is the electrical resistivity. This parameter is influenced by several factors, such as degree of saturation, degree of hydration and chemical composition of the material. This work evaluates the effect of the variation of such factors on the resistivity in three concrete mixtures being the first a reference sample (without addition) and the other two with addition the first with fly ash and the second with rice husk silica. The results of the work show that the higher the degree of hydration, the greater the resistivity of the material, regardless of the degree of saturation and type of addition. In this context, the higher the resistance, the resistivity is also high. In addition, the two mixtures with additions presented higher resistivity than the reference sample, with very high values in the rice husk silica mixture. In this way, it is possible to conclude that the more active the addition, the greater the resistivity and protection values of the concrete.

Keywords: Electrical resistivity, absorption, resistance, fly ash, rice husk silica. 
OLIVEIRA, I. A.; ET AL.. EFEITO DO GRAU DE HIDRATAÇÃO E DE SATURAÇÃO DO CONCRETO NAS LEITURAS DE RESISTIVIDADE ELÉTRICA. $2^{\circ}$ Simpósio Paranaense de Patologia das Construções (2 SPPC), artigo 2SPPC1019, pp. 224-236,

\section{Introdução}

Atualmente são muitos os métodos utilizados para a caracterização de um material e podem ser subdivididos pelo princípio que se baseiam e em função das propriedades que medem. Além dos ensaios mecânicos, pode-se optar pelos ensaios químicos, físico-químicos e até microestruturais, ensaios estes que permitem analisar com maior grau de confiabilidade as consequências da interação entre o material e o ambiente [9].

As estruturas de concreto, por meio da interação que possuem com o meio ambiente, estão submetidas a diversos tipos de agentes físicos e químicos, que fazem com que as obras se degradem ao longo do tempo. Uma consequência danosa desta interação é a corrosão das armaduras em estruturas de concreto armado, que tem sido citada como a principal causa da sua deterioração [1]. Um dos principais parâmetros utilizados para o monitoramento da corrosão é a resistividade elétrica, que muitas vezes é decisiva para se estimar a velocidade de sua corrosão, pois controla o fluxo de íons através de solução aquosa presente nos poros do concreto, sendo consideravelmente sensível ao teor de umidade e à temperatura do concreto. Contudo, é importante salientar que a resistividade não é o fator único de monitoramento de uma estrutura de concreto armado [8].

A resistividade elétrica do concreto pode ser usada em combinação com outras técnicas não destrutivas, como mapas de potencial e taxa de corrosão. A baixa resistividade do concreto está relacionada à rápida penetração de cloretos e uma taxa alta de corrosão. Adicionalmente os mapas de resistividade podem mostrar as áreas mais porosas, nas quais a penetração provavelmente acontecerá de maneira mais rápida e a futura taxa de corrosão poderá ser mais alta; em consequência, medidas preventivas podem ser tomadas a partir dessa informação [11].

Em diversos países, os gastos anuais com reparos, recuperações e reposições de elementos estruturais afetados por corrosão da armadura são expressivamente elevados, e os prejuízos econômicos e sociais são grandes [2, 3]. Por conta disso, a avaliação e os estudos que relacionados à durabilidade das estruturas de concreto são essenciais para que o problema seja minimizado.

Depois da ocorrência do dano, a resistividade é relevante para determinar as possíveis ações de manutenção, assim como os possíveis métodos eletroquímicos de reparo, ainda, as medidas de resistividade podem dar informações extras, como mostrar onde a corrosão é mais forte na estrutura [11].

Entende-se por resistividade do concreto a relação entre uma voltagem aplicada e a corrente resultante em uma unidade de célula, isto é, uma geometria específica independentemente das propriedades do material, as quais descrevem ou determinam a resistência elétrica do mesmo, sendo que condutividade é o inverso da resistividade. A unidade de medida da resistividade é usualmente adotada como $\Omega$.m (ohm x metro).

Existem diversos fatores que influenciam na resistividade do material, como por exemplo, a condutividade da solução nos poros do material assim como o número e distribuição destes poros saturados como resultado da interação com o meio ambiente [11]. Parte desta porosidade está relacionada ao excesso de água utilizado 
OLIVEIRA, I. A.; ET AL.. EFEITO DO GRAU DE HIDRATAÇÃO E DE SATURAÇÃO DO CONCRETO NAS LEITURAS DE RESISTIVIDADE ELÉTRICA. $2^{\circ}$ Simpósio Paranaense de Patologia das Construções (2 SPPC), artigo 2SPPC1019, pp. 224-236,

na mistura do concreto que, após a solidificação, tende a evaporar fazendo do poro capilar uma via de acesso ao interior da peça [4]. Além disso, um fator agravante é que os diversos tipos de transporte de massa podem ocorrer simultaneamente, com intensidades variadas, o que dificulta a definição de um modelo de transporte de massa e, consequentemente, a proposição de modelos de vida útil precisos [5].

A relação água/cimento e a porosidade são características que têm forte impacto de variação na resistividade elétrica do concreto. Logo, quando a porosidade for alta, a resistividade do material tende a ser alta para concretos com baixa umidade, devido à redução da quantidade de eletrólito. E quando o concreto estiver saturado, esta alta porosidade reduz a sua resistividade deixando-o mais condutivo, pois a água e os íons liberados pela dissolução dos minerais do próprio concreto formam substâncias condutivas [6]. Sendo assim, para uma umidade relativa constante e em condições estacionárias, a resistividade do concreto é aumentada usando baixas relações a/c, tempos de cura extensos (hidratação alta) ou pela adição de minerais reativos como escórias de alto forno, cinza volante ou sílica fume [11].

Ainda, através da medição da variação da resistividade elétrica é possível avaliar, além da probabilidade de corrosão na estrutura, as mudanças na microestrutura do concreto. Essas mudanças podem ser relacionadas às adições utilizadas ou até mesmo ao grau de hidratação que é correlacionado com a idade da amostra. $O$ volume da água evaporável na pasta em um concreto saturado varia de aproximadamente $60 \%$ na hora da mistura para aproximadamente $40 \%$ quando 0 cimento está completamente hidratado. Esta água contém íons, primeiramente $\mathrm{Na}^{+}$, $\mathrm{K}^{+}, \mathrm{Ca}^{++}, \mathrm{SO}_{4}^{--}$e $\mathrm{OH}^{-}$, cujas concentrações variam com o tempo. A concentração de alguns íons aumenta enquanto que a de outros diminui. Assim, com a evolução da hidratação a porosidade vai diminuindo e os vazios, que inicialmente eram ocupados pelo eletrólito, vão sendo preenchidos pelos compostos que se formam no decorrer do tempo [7]. Um estudo que avaliou o efeito das adições minerais na resistividade elétrica de concretos convencionais, concluiu que, em função da hidratação e densificação existe um incremento na resistividade elétrica dos concretos, em maior ou menor intensidade. O incremento no valor da resistividade está relacionado ao tipo de adição ou de cimento [6].

Sendo que ditas hipóteses estão sujeitas ainda a discussão no que diz respeito ao efeito de algumas variáveis, o presente trabalho pretende contribuir para o melhor entendimento do comportamento da resistividade no concreto com adições exposto a diferentes níveis de saturação e hidratação.

\section{Materiais e métodos}

O trabalho tem como foco testar a sensibilidade do ensaio de resistividade elétrica para detecção do avanço da hidratação do concreto, além do comportamento do mesmo quanto ao grau de saturação, que será medido através da disposição dos corpos de prova a ambientes diferentes onde a umidade relativa do ar será também distinta. As variáveis independentes correspondem aos aspectos julgados como importantes pontos de pesquisa, já que têm influência nas características do material e nas leituras de resistividade elétrica do eletrólito. A seguir estão indicadas as variáveis independentes deste trabalho: 
OLIVEIRA, I. A.; ET AL.. EFEITO DO GRAU DE HIDRATAÇÃO E DE SATURAÇÃO DO CONCRETO NAS LEITURAS DE RESISTIVIDADE ELÉTRICA. $2^{\circ}$ Simpósio Paranaense de Patologia das Construções (20 SPPC), artigo 2SPPC1019, pp. 224-236, 2017. DOI: $10.4322 / 2$ SPPC.2017.019

- Tempo de cura correspondente a cinco idades diferentes $(3,7,28,63$ e 91 dias);

- Adição pozolânica, sendo dois tipos (tabela 1); a primeira composta por cinza volante e a segunda composta por sílica de casca de arroz, ambas utilizadas com teor de incorporação de $30 \%$ em substituição ao cimento nos concretos produzidos (referência sem adição, substituição do cimento em $30 \%$ de cinza volante e substituição do cimento em $30 \%$ de sílica de casca de arroz);

- Como parâmetros fixados, pode-se citar o traço do concreto $(1: 2,70: 3,20)$, relação água/cimento de 0,58 e consistência medida pelo abatimento do tronco de cone de $(100 \pm 20) \mathrm{mm}$.

Tabela 1: Composição química - Cinza Volante e Sílica de Casca de Arroz

\begin{tabular}{c|c|c|c|c|c|c|c|c|c|c|c|c|c|c|c}
\hline \multirow{2}{*}{ Adição } & \multicolumn{10}{|c|}{ Composição Química (\%) } \\
\cline { 2 - 13 } & $\mathrm{SiO}_{2}$ & $\mathrm{~K}_{2} \mathrm{O}$ & $\mathrm{Fe}_{2} \mathrm{O}_{3}$ & $\mathrm{CaO}$ & $\mathrm{Al}_{2} \mathrm{O}_{3}$ & $\mathrm{P}_{2} \mathrm{O}_{5}$ & $\mathrm{TiO}_{2}$ & $\mathrm{SO}_{3}$ & $\mathrm{MgO}$ & $\mathrm{ZnO}$ & $\mathrm{MnO}$ & $\mathrm{CuO}$ & $\mathrm{Rb}_{2} \mathrm{O}$ & $\mathrm{Tm}_{2} \mathrm{O}_{3}$ & $\mathrm{SrO}$ \\
\hline $\begin{array}{c}\text { Sílica } \\
\text { casca } \\
\text { arroz }\end{array}$ & 88,9 & 4,2 & 0,1 & 1,1 & 2,4 & 0,2 & - & 2,1 & - & 0,01 & 0,9 & 0,02 & 0,02 & - & - \\
\hline $\begin{array}{c}\text { Cinza } \\
\text { Volante }\end{array}$ & 57,8 & 3,0 & 6,2 & 1,6 & 26,3 & 0,1 & 1,3 & 0,3 & 0,8 & 0,1 & 0,1 & - & 0,1 & - & 0,1 \\
\hline
\end{tabular}

As variáveis dependentes são os ensaios propriamente ditos, realizados no experimento, que estão descritos abaixo.

- Resistência à compressão axial nas quatro idades;

- Absorção de água por sucção capilar;

- Absorção de água por imersão;

- Resistividade do concreto.

As duas avaliações de influência, propostas neste estudo, quais sejam, grau de hidratação e grau de saturação, serão avaliadas através do acompanhamento da resistividade dentro da câmara úmida e através do monitoramento da absorção de água de ambientes com diferentes umidades relativas do ar, respectivamente. $O$ detalhamento dessas condições está descrito no item 2.1.

\subsection{Planejamento do experimento}

Para realização dos ensaios foram moldados corpos de prova cilíndricos $(10 \mathrm{~cm} x$ $20 \mathrm{~cm}$ ) na quantidade obtida através da consideração das variáveis apresentadas a seguir:

- 3 concretos produzidos (referência, subst.cimento $30 \%$ cinza volante, subst.cimento $30 \%$ sílica de casca de arroz);

- 5 idades de avaliação (3, 7, 28, 63 e 91);

- 6 repetições (3 corpos de prova para o ensaio de resistência à compressão e 3 corpos de prova para o ensaio de absorção).

Os concretos fabricados neste estudo foram produzidos no Laboratório de Materiais e Estruturas (LAME), da Universidade Federal do Paraná, seguindo as normas vigentes. Para produção dos concretos foi utilizado cimento tipo CPII-F, areia média natural, brita 1 e água potável, além das adições (cinza volante e sílica de casca de arroz). Além destes, é importante ressaltar que foi utilizado também aditivo 
OLIVEIRA, I. A.; ET AL.. EFEITO DO GRAU DE HIDRATAÇÃO E DE SATURAÇÃO DO CONCRETO NAS LEITURAS DE RESISTIVIDADE ELÉTRICA. $2^{\circ}$ Simpósio Paranaense de Patologia das Construções (2 SPPC), artigo 2SPPC1019, pp. 224-236,

superplasticante, condicionado à avaliação do abatimento estabelecido, nos teores de $0,5 \%, 0,75 \%$ e $1,0 \%$, para o concreto de referência, o concreto com adição de cinza volante e o concreto com adição de sílica de casca de arroz, respectivamente. Foram fabricados 6 corpos de prova para cada tipo de concreto e idade de avaliação, sendo 3 utilizados para medição da resistência à compressão e 3 para os ensaios de absorção por sucção capilar e absorção por imersão (que foram medidos no mesmo corpo de prova). A medida de resistividade foi realizada neste último grupo de 3 corpos de prova onde foram feitas as medições de absorção.

O procedimento para realização do ensaio de absorção por sucção capilar seguiu as recomendações da NBR 9779/2012, sendo que, a secagem inicial em estufa, até constância de massa, foi realizada à uma temperatura de $60^{\circ} \mathrm{C}$, para que não houvessem danos à microestrutura do concreto. Depois da finalização das leituras do ensaio de absorção por sucção capilar, os corpos de prova foram acondicionados em câmara seca, com temperatura e umidade controlada, até secagem completa verificada através de constância de massa.

Depois de secos, os corpos de prova foram submergidos em água para determinação da absorção por imersão, conforme diretrizes da NBR 9778/2005. Contabilizando apenas a duração dos dois ensaios de absorção, sem contar o tempo de secagem em estufa até constância de massa. Foram decorridos 6 dias (72 horas para cada ensaio). Sendo assim, a avaliação da absorção (tanto por sucção quanto por imersão) nos corpos de prova de idade de 3 e 7 dias foi comprometida, já que o tempo de ensaio é muito próximo à idade do concreto a ser ensaiado. Deste modo, o resultado do ensaio de absorção pode não ser assertivo, já que as reações de hidratação serão alteradas, inclusive possivelmente interrompidas pela secagem em estufa. Por conta disso, as medidas de absorção foram avaliadas nos corpos de prova com idade a partir de 28 dias. De qualquer forma, é importante ressaltar que as leituras de resistividade foram realizadas em todas as idades.

Deste modo, o acompanhamento da resistividade dentro da câmara úmida determinou o monitoramento do efeito do avanço da hidratação. Já o efeito do grau de saturação, foi avaliado através da medida da resistividade no estado seco e posteriormente nas medições realizadas a medida que o concreto foi absorvendo água. Com esses dados, foi possível a realização dos gráficos de saturação e hidratação, avaliando inclusive o efeito das duas adições, através das medidas de resistividade elétrica.

\subsection{Resistividade do concreto}

As leituras de resistividade foram realizadas com o equipamento Resipod Family da Proceq, de fabricação suíça. O método de ensaio foi o de medição de campo para solos, conhecido como Sonda Wenner, ou método de quatro pontos. Normatizado pela ASTM G-57 (2012), este método é um procedimento que consiste na medição da resistividade elétrica entre as faces opostas de uma unidade de material [10]. Contudo, aplica-se atualmente em estruturas de concreto. 


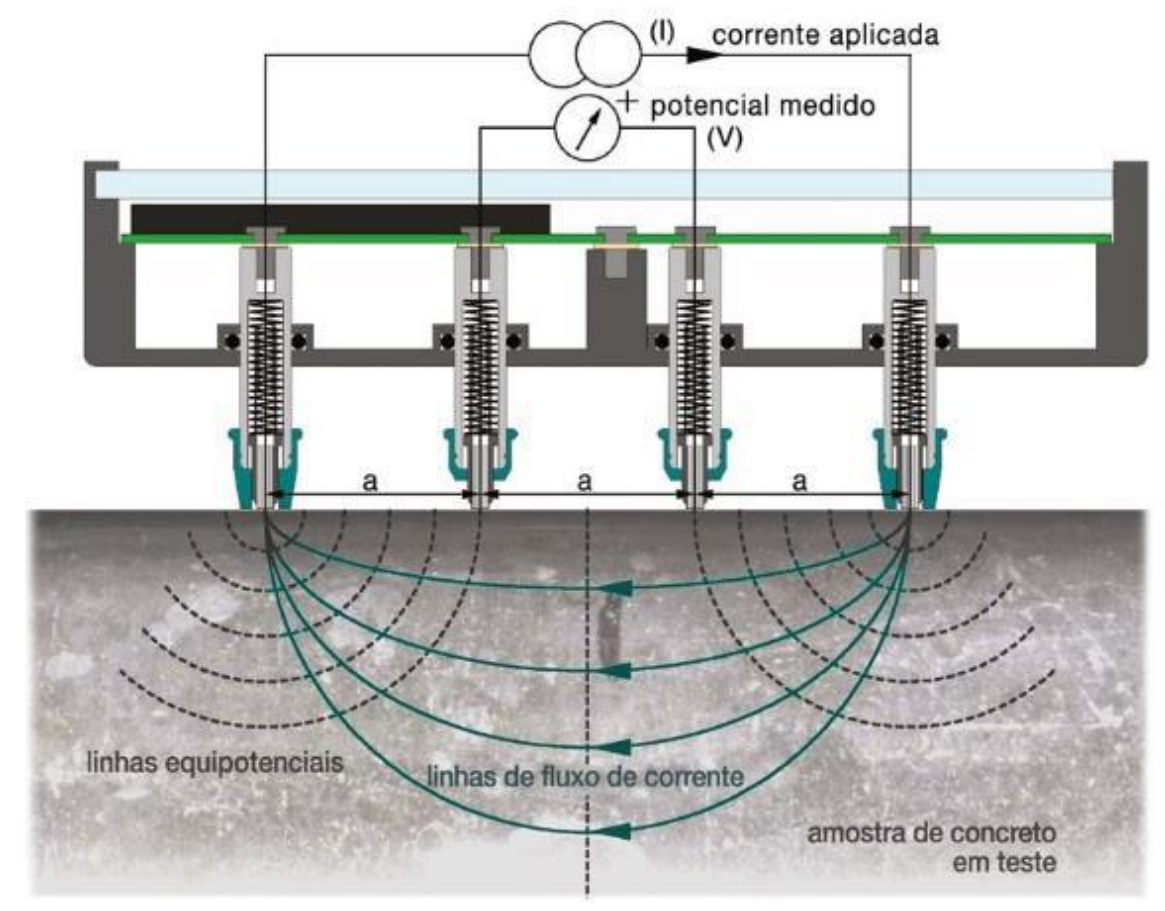

Figura 1: Princípio de medição - Sonda Wenner

A sonda utilizada consiste em quatro eletrodos firmemente fixados para manter 0 espaçamento entre eles (figura 1). Cada um dos eletrodos faz contato com a superfície do concreto através de um eletrólito condutivo, usualmente é usada uma esponja molhada ou um plug de madeira molhada, sendo que o equipamento utilizado contempla esponjas pequenas adaptáveis para cada um dos seus eletrodos.

Conforme recomenda a literatura [11], antes das medições serem aferidas, a superfície do concreto deve ser levemente umedecida para melhorar o contato com o eletrodo, para isto, foram feitos toques rápidos com uma esponja molhada sobre a superfície do concreto para que a leitura do aparelho seja confiável. Foram feitas 6 leituras em cada corpo de prova, obedecendo a angulação de $60^{\circ}$ de uma leitura para a outra, sendo determinado o valor médio das mesmas, de forma a obter um conjunto representativo de dados.

\section{Resultados}

Os resultados das resistividades $(\Omega$.m) e Resistências à compressão $(\mathrm{MPa})$ aferidas aos 7, 28, 63 e 91 dias dos corpos de provas Referência, Cinza Volante e Sílica de Casca de Arroz encontra-se na tabela 2. 
OLIVEIRA, I. A.; ET AL.. EFEITO DO GRAU DE HIDRATAÇÃO E DE SATURAÇÃO DO CONCRETO NAS LEITURAS DE RESISTIVIDADE ELÉTRICA. $2^{\circ}$ Simpósio Paranaense de Patologia das Construções (20 SPPC), artigo 2SPPC1019, pp. 224-236, 2017. DOI: $10.4322 / 2$ SPPC.2017.019

Tabela 2: Resultados - Resistividade ( $2 . \mathrm{m})$ e Resistência (MPa)

\begin{tabular}{|c|c|c|c|c|c|c|c|c|c|}
\hline \multirow{2}{*}{ Amostras } & \multirow{2}{*}{$\begin{array}{l}\text { Idade } \\
\text { (dias) }\end{array}$} & \multicolumn{4}{|c|}{ Resistividade ( $\Omega . \mathrm{m}$ ) } & \multicolumn{4}{|c|}{ Resistência (MPa) } \\
\hline & & 7 & 28 & 63 & 91 & 7 & 28 & 63 & 91 \\
\hline \multirow{2}{*}{ Referência } & Média & 2,9 & 3,8 & 4,6 & 4,5 & 36,6 & 45,1 & 47,4 & 44,6 \\
\hline & Desvio Padrão & 0,12 & 0,16 & 0,26 & 0,48 & 2,14 & 1,28 & 2,22 & 2,78 \\
\hline \multirow{2}{*}{ Cinza Volante } & Média & 2,3 & 4,3 & 6,6 & 10,1 & 27,8 & 35,6 & 43,5 & 43,5 \\
\hline & Desvio Padrão & 0,11 & 0,36 & 0,41 & 0,87 & 2,00 & 0,90 & 1,05 & 2,50 \\
\hline \multirow{2}{*}{$\begin{array}{c}\text { Sílica de Casca de } \\
\text { Arroz }\end{array}$} & Média & 2,4 & 8,2 & 29,2 & 34,3 & 30,7 & 49,4 & 55,0 & 59,2 \\
\hline & Desvio Padrão & 0,20 & 0,46 & 1,09 & 1,54 & 1,50 & 0,87 & 0,94 & 0,45 \\
\hline
\end{tabular}

O resultado de maior resistência para o traço referência foi adquirido aos 63 dias, atingindo 47,4 MPa à compressão, coerentemente o resultado de resistividade atingiu melhores resultados também na idade de 63 dias, adquirindo 4,6 $\Omega$.m. O resultado de maior resistência para o traço com cinza volante estabilizou-se após os 63 dias em cerca de 43,5 MPa à compressão, já a resistividade atingiu melhores resultados na idade de 91 dias, adquirindo 10,1 $\Omega$.m. O resultado de maior resistência para o traço com sílica de casca de arroz foi atingido aos 91 dias, e atingiu de 59,2 MPa à compressão, já a resistividade atingiu melhores resultados na idade de 91 dias, adquirindo $34,3 \Omega$.m.

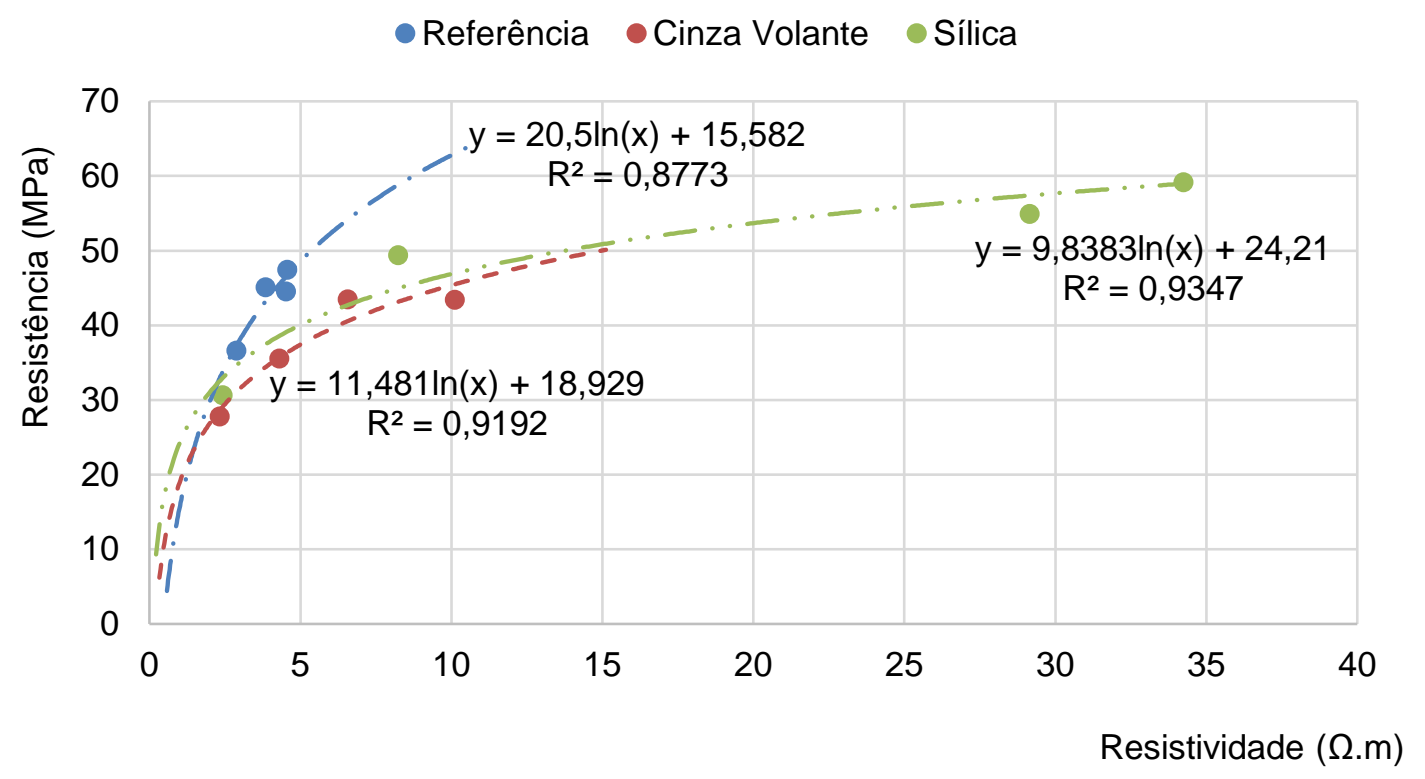

Figura 2: Correlação entre resistência x resistividade (28, 63 e 91 dias)

Na figura 2 é apresentada a correlação entre a resistência e resistividade nas idades de 7, 28, 63 e 91 dias. O traço referência foi a menor correlação, apresentando $\mathrm{R}^{2}=$ 0,8773 . O traço com substituição por cinza volante apresentou boa correlação, $R^{2}=$ 0,9192 . Já o traço com substituição por sílica de casca de arroz apresentou correlação $\mathrm{R}^{2}=0,9347$, se mostrando superior às demais relações.

Abaixo são apresentados gráficos estatísticos em forma de boxplot para representação das amostras dos corpos de prova Referência (figura 3), Cinza Volante (figura 4) e Sílica de Casca de Arroz (figura 5). Foi escolhida esta forma de representação porque visualmente é a que melhor fornece informações sobre a variabilidade dos dados e valores atípicos que podem influenciar o ensaio 
OLIVEIRA, I. A.; ET AL.. EFEITO DO GRAU DE HIDRATAÇÃO E DE SATURAÇÃO DO CONCRETO NAS LEITURAS DE RESISTIVIDADE ELÉTRICA. $2^{\circ}$ Simpósio Paranaense de Patologia das Construções (20 SPPC), artigo 2SPPC1019, pp. 224-236, 2017. DOI: $10.4322 / 2$ SPPC.2017.019
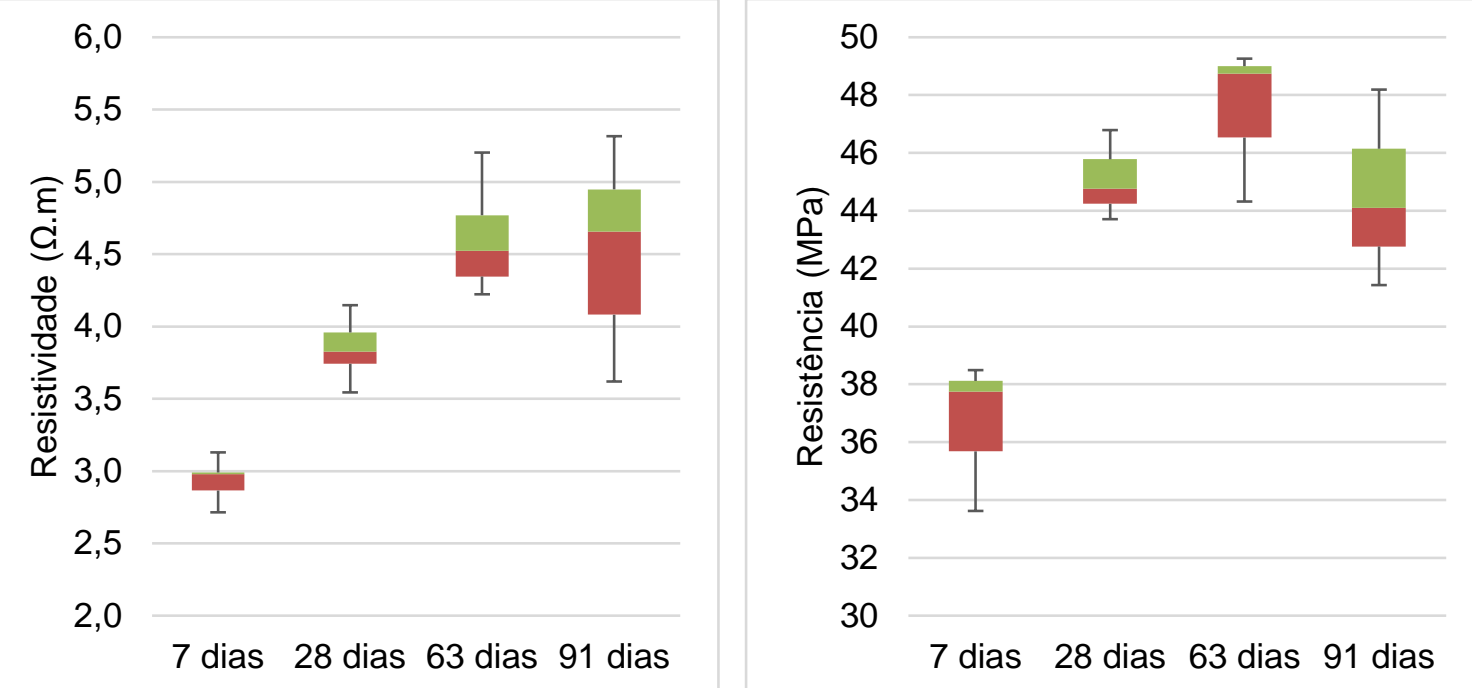

Figura 3: Gráfico estatístico da Resistividade e Resistência (CP - Referência)
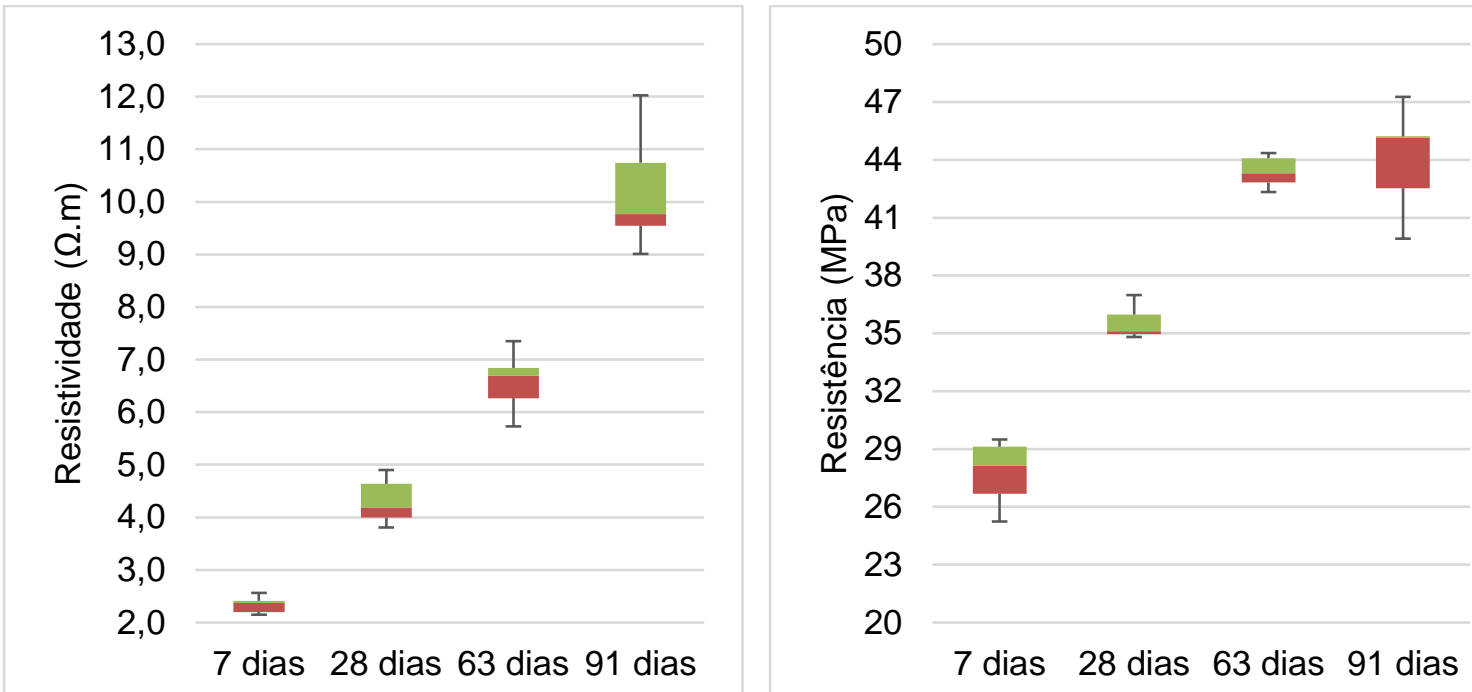

Figura 4: Gráfico estatístico da Resistividade e Resistência (CP - Cinza Volante)
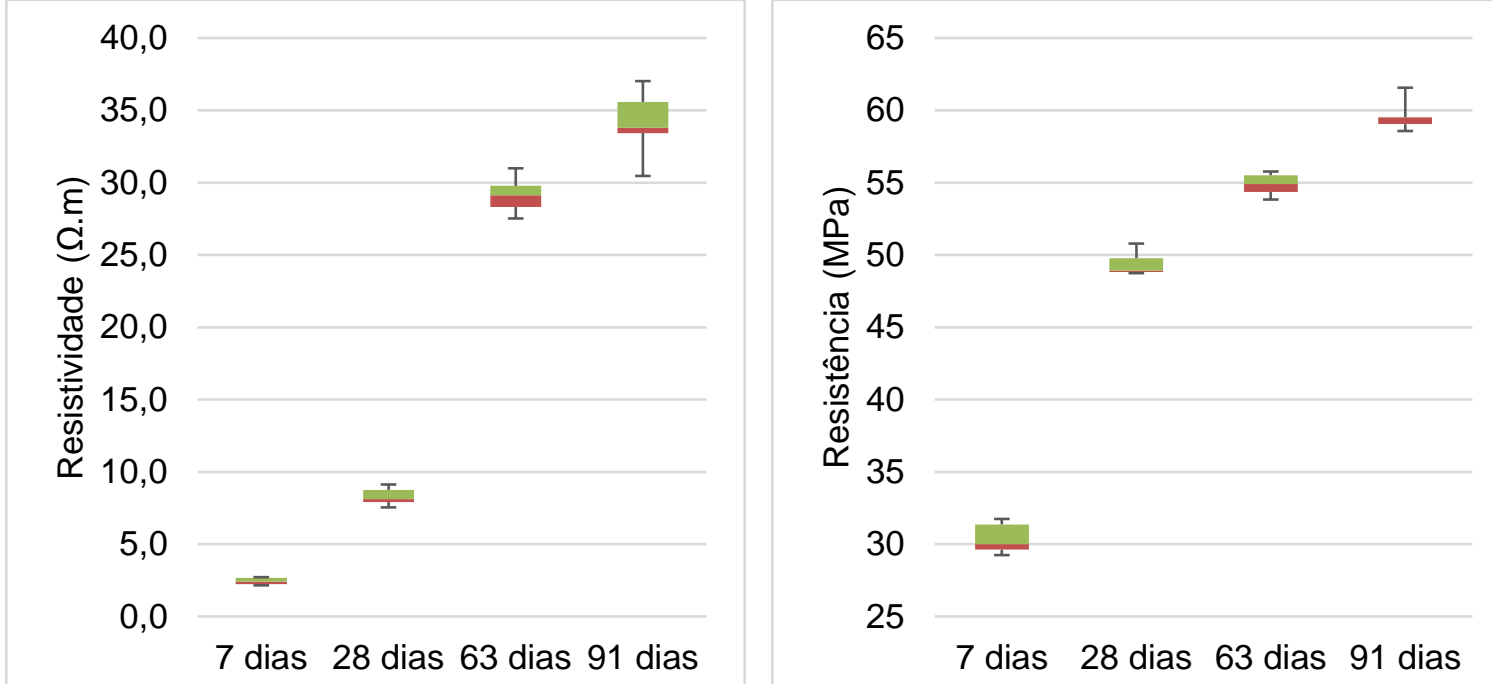

Figura 5: Gráfico estatístico da Resistividade e Resistência (CP - Sílica de Casca de Arroz) 
OLIVEIRA, I. A.; ET AL.. EFEITO DO GRAU DE HIDRATAÇÃO E DE SATURAÇÃO DO CONCRETO NAS LEITURAS DE RESISTIVIDADE ELÉTRICA. $2^{\circ}$ Simpósio Paranaense de Patologia das Construções (20 SPPC), artigo 2SPPC1019, pp. 224-236, 2017. DOI: $10.4322 / 2$ SPPC.2017.019

Nas figuras 6, 7 e 8 são representados os gráficos que determinam a absorção de água através da ascensão capilar e da resistividade sobre influência desta absorção. As leituras foram efetuadas conforme indicação da NBR 9779, sempre executando as leituras das massas dos corpos-de-prova e das resistividades com 3h, $6 \mathrm{~h}, 24 \mathrm{~h}, 48 \mathrm{~h}$ e $72 \mathrm{~h}$.

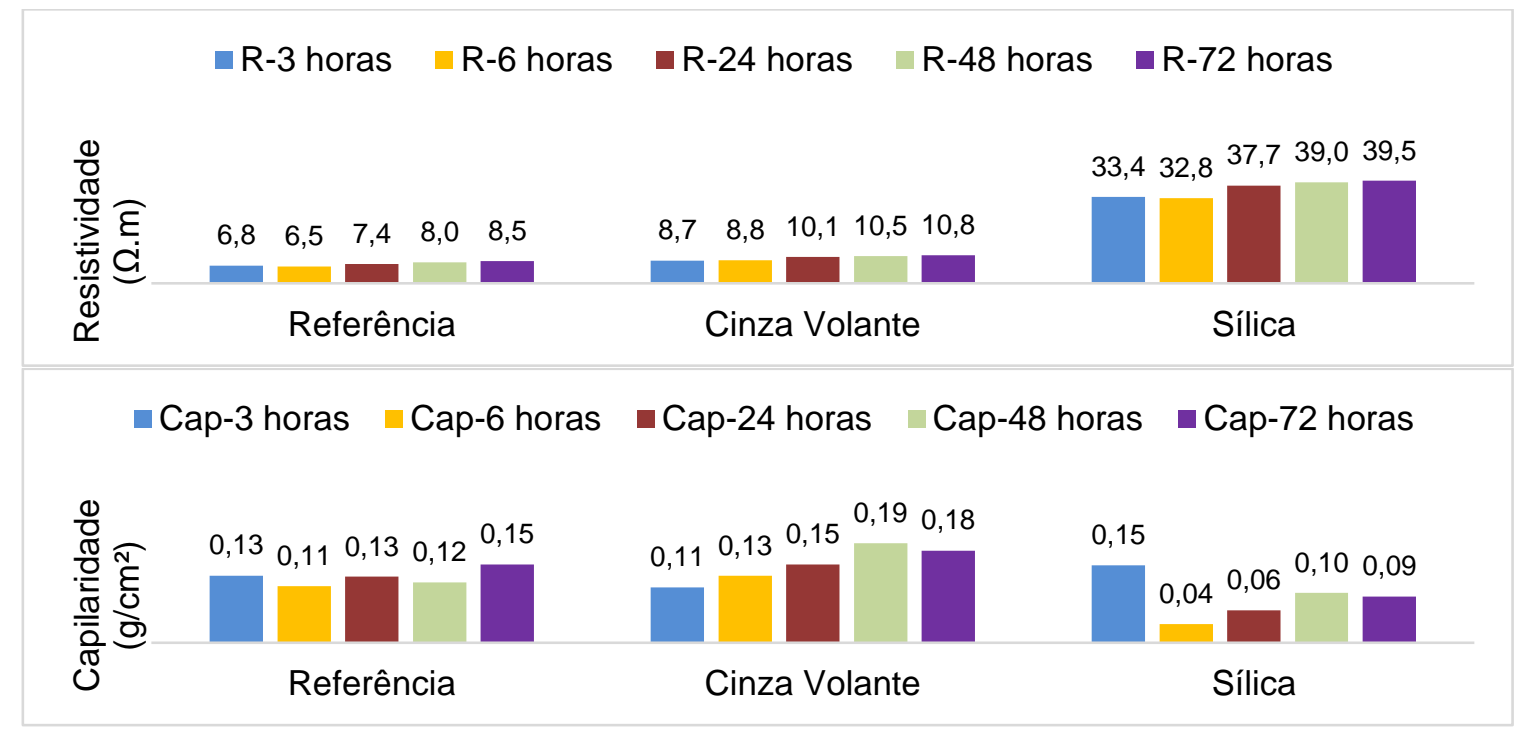

Figura 6: Resultado da Resistividade x Capilaridade (3, 6, 24, 48 e 72 horas) - 28 dias

Para os três traços, na idade de 28 dias, não há influência negativa da capilaridade nas leituras de resistividade. Conforme aumenta o tempo dos corpos-de-prova no ensaio de capilaridade há um pequeno aumento das leituras de resistividade.

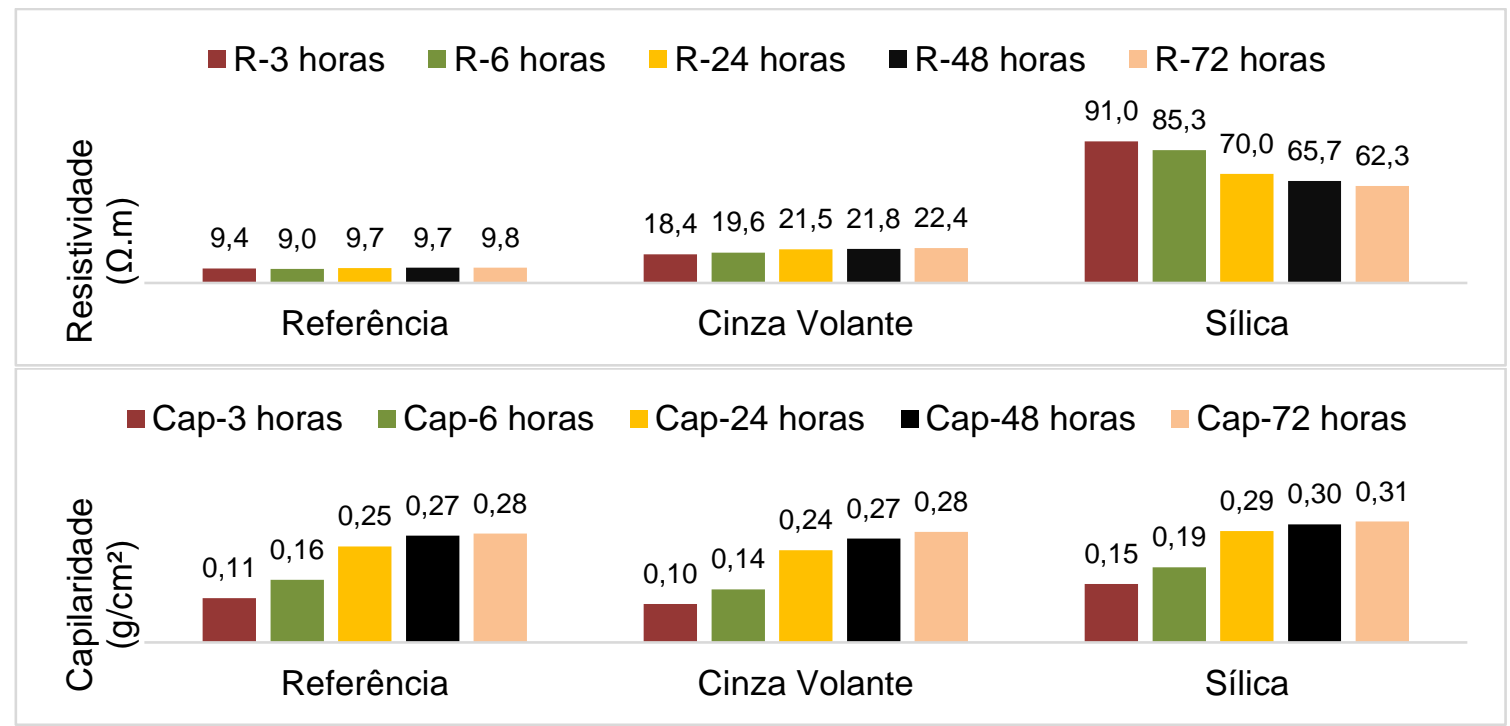

Figura 7 - Resultado da Resistividade x Capilaridade (3, 6, 24, 48 e 72 horas) - 63 dias

Para o traço referência e cinza volante, aos 63 dias, conforme aumenta a capilaridade há um leve aumento das leituras da resistividade. Já para o traço com sílica, a partir das 3 horas de ensaio o valor da capilaridade sofre aumento considerável de 0,15 
OLIVEIRA, I. A.; ET AL.. EFEITO DO GRAU DE HIDRATAÇÃO E DE SATURAÇÃO DO CONCRETO NAS LEITURAS DE RESISTIVIDADE ELÉTRICA. $2^{\circ}$ Simpósio Paranaense de Patologia das Construções (20 SPPC), artigo 2SPPC1019, pp. 224-236,

$\mathrm{g} / \mathrm{cm}^{2}$ para $0,31 \mathrm{~g} / \mathrm{cm}^{2}$ às 72 horas, fator que faz com a resistividade diminua de 91 para $62,3 \Omega . m$.

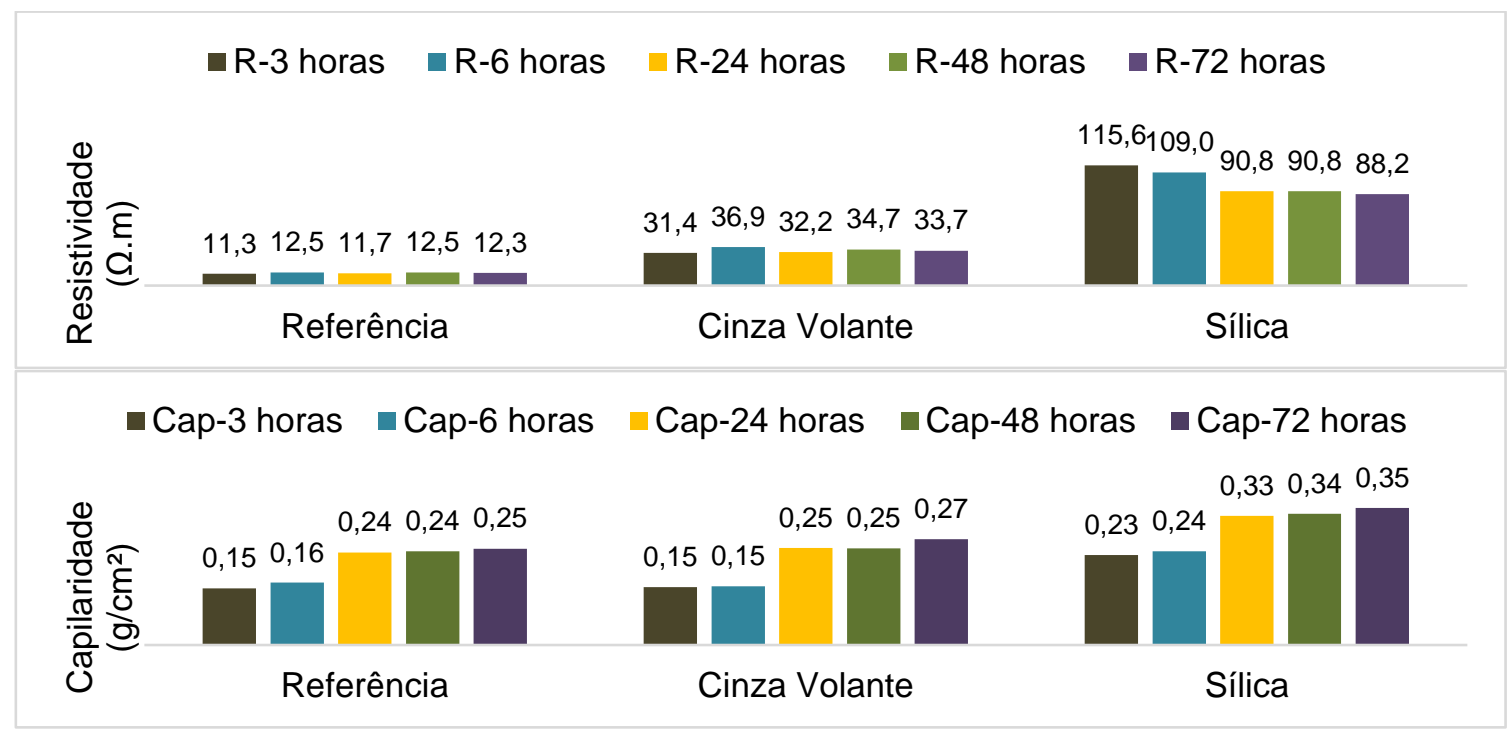

Figura 8 - Resultado da Resistividade x Capilaridade (3, 6, 24, 48 e 72 horas) - 91 dias

Para o traço referência e cinza volante, aos 91 dias, apesar de aumentar o valor da capilaridade a leitura da resistividade se mantem estável com pequenas variações, conforme o gráfico da figura 8 acima. Para o traço com sílica, observa-se que já na leitura de $3 \mathrm{~h}$ há grande absorção por capilaridade, $0,23 \mathrm{~g} / \mathrm{cm}^{2}$, atingindo nas $72 \mathrm{~h}$ de ensaio $0,35 \mathrm{~g} / \mathrm{cm}^{2}$. Nas leituras de resistividade, aos 91 dias, para o traço com sílica, comporta-se analogamente às leituras dos de 63 dias, com diminuição da resistividade ao longo das 72 horas de ensaio.

Nos gráficos abaixo, representados pelas figuras 9, 10 e 11, são apresentados os resultados dos ensaios de imersão e resistividade. Conforme a NBR 9778, a massa foi aferida sempre após $24 \mathrm{~h}, 48 \mathrm{~h}$ e $72 \mathrm{~h}$. Juntamente com a medição da massa foi aferida a leitura de resistividade nestes intervalos.

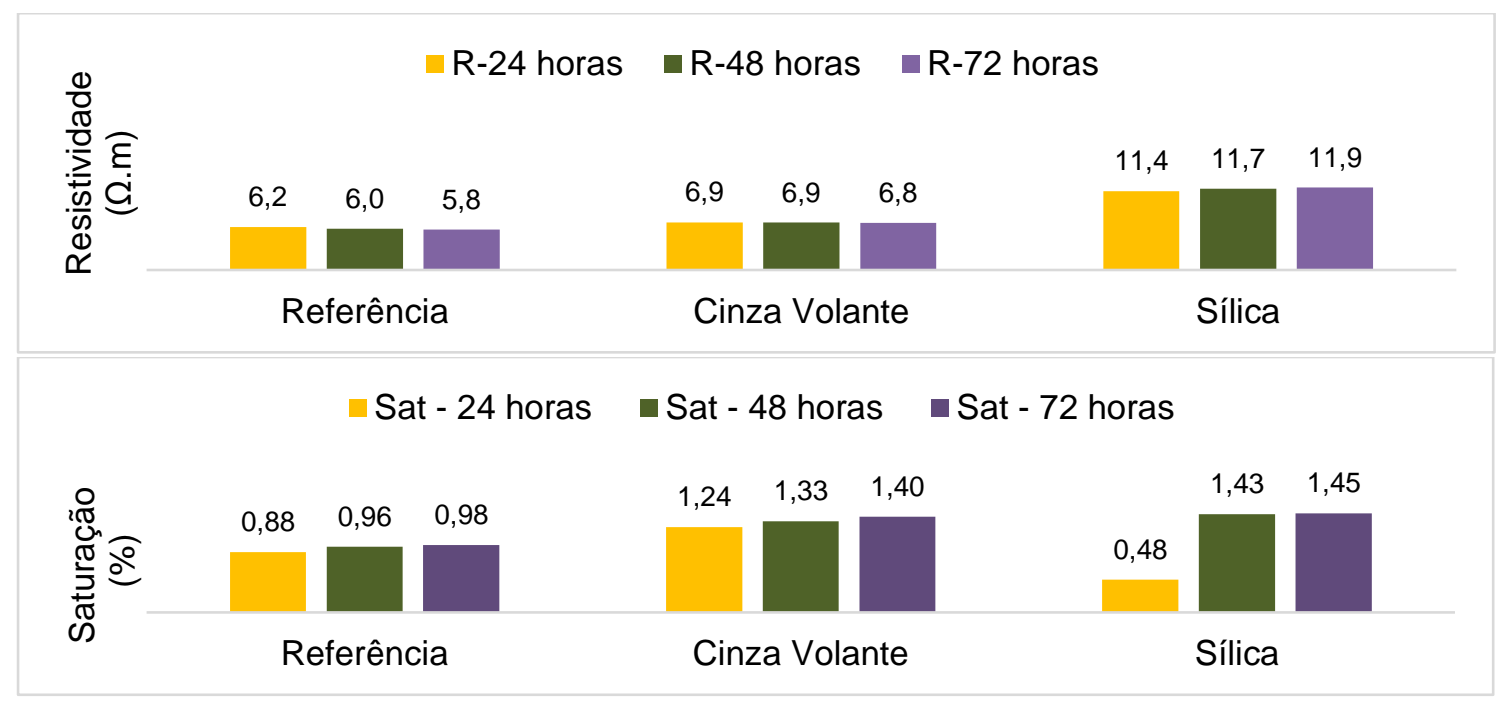

Figura 9 - Resultado da resistividade x saturação (24, 48 e 72 horas) - 28 dias 
Conforme o gráfico representado pela figura 9, com o aumento da saturação dos corpos de prova não houve significativo aumento e nem redução da resistividade dos traços referência, cinza volante ou sílica.

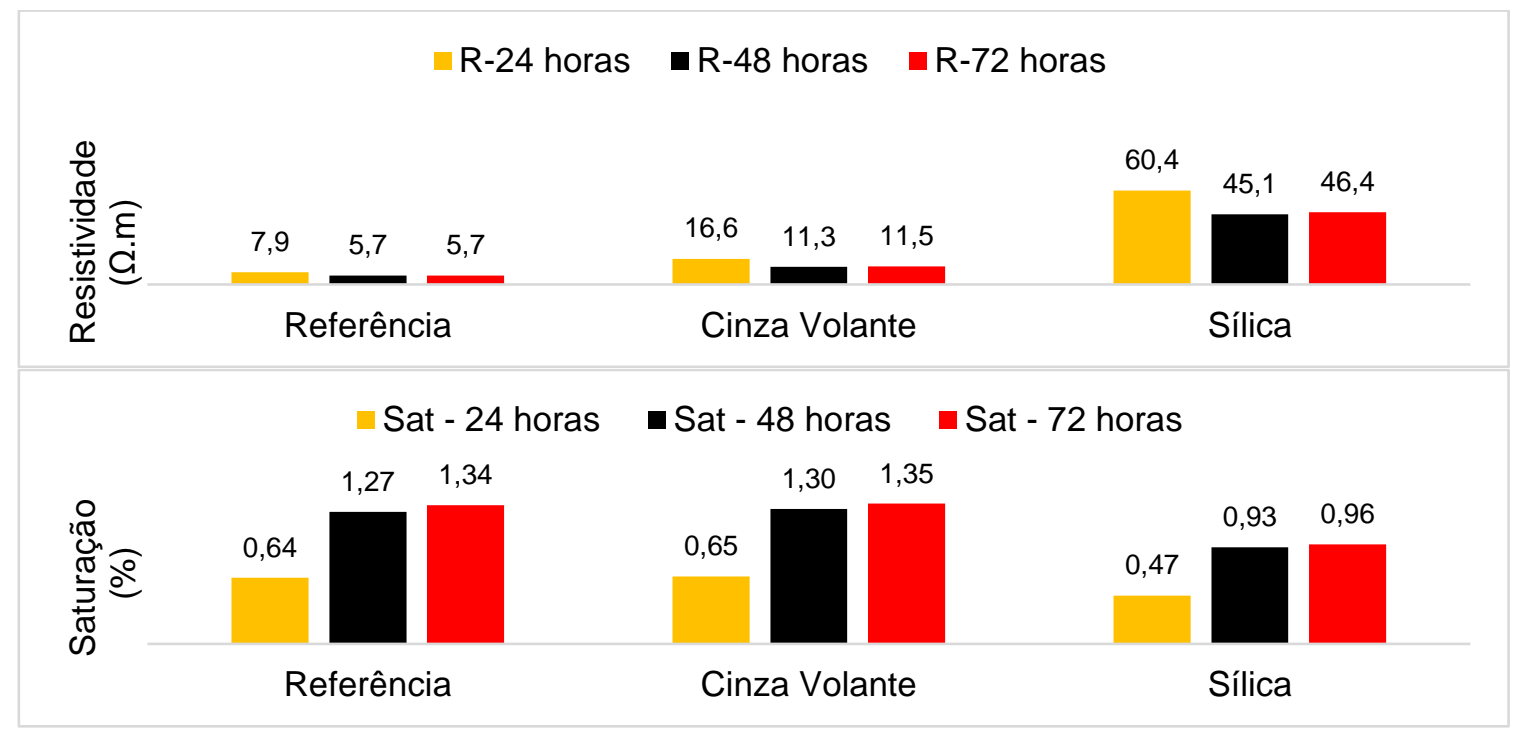

Figura 10 - Resultado da resistividade x saturação (24, 48 e 72 horas) - 63 dias

Os resultados para a idade de 63 dias já apresenta variação maior que as de 28 dias. No traço referência com o aumento das saturações há leve diminuição das resistividades ao longo das 72 horas de ensaio. Fato que é similar no traço de cinza volante, já no traço com sílica através do incremento da saturação de 3h para 6h há um decréscimo maior da resistividade de 60,4 para $45,1 \Omega$.m, atingindo patamar de

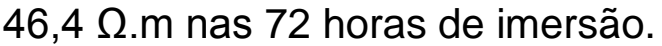

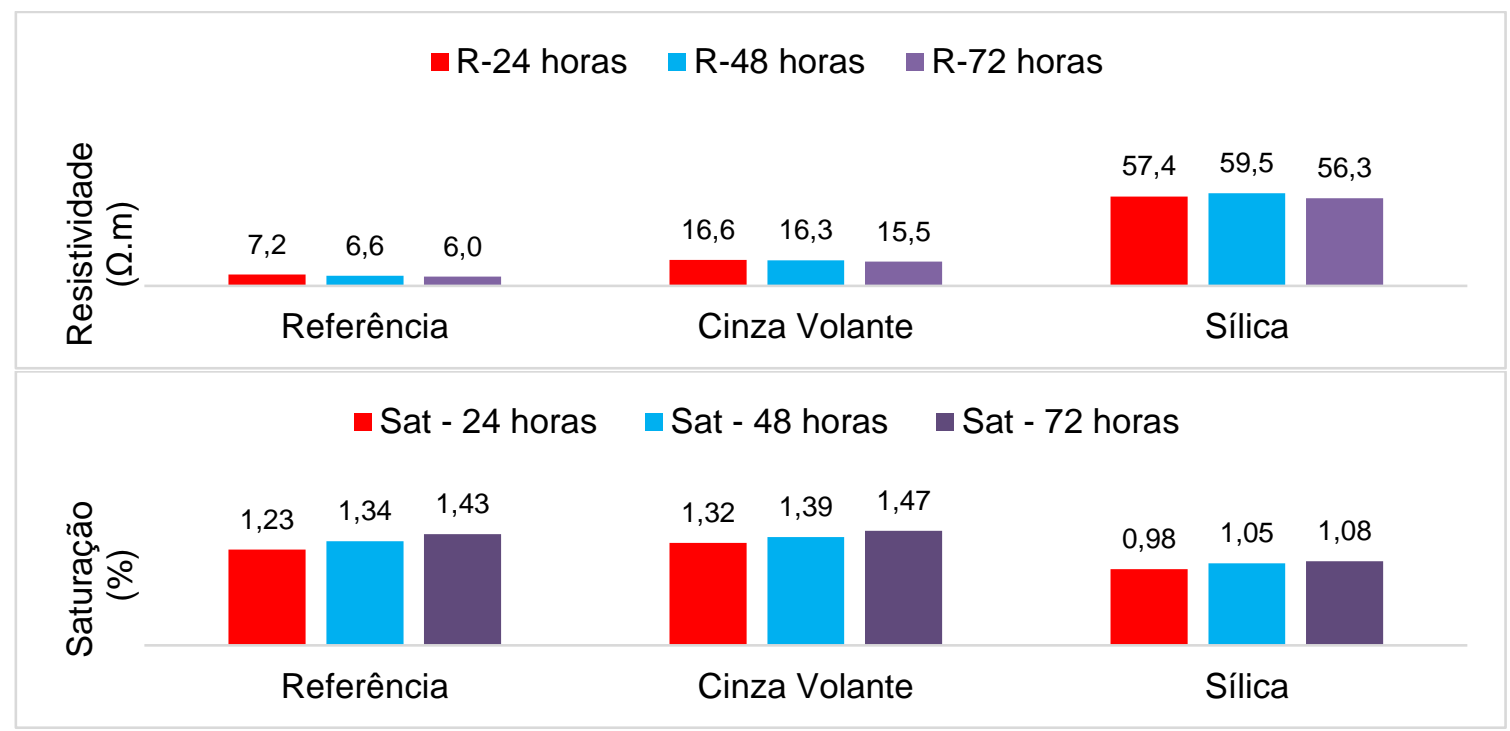

Figura 11 - Resultado da Resistividade x Saturação (24, 48 e 72 horas) - 91 dias

Para o traço referência e cinza volante, aos 91 dias, já nas primeiras 24 horas de ensaio apresentam alta saturação não tendo grande variação até as 72 horas finais. Da mesma forma que a saturação, a resistividade sofre pequena variação no referência e cinza volante, já no traço com sílica a resistividade aumenta no período 
OLIVEIRA, I. A.; ET AL.. EFEITO DO GRAU DE HIDRATAÇÃO E DE SATURAÇÃO DO CONCRETO NAS LEITURAS DE RESISTIVIDADE ELÉTRICA. $2^{\circ}$ Simpósio Paranaense de Patologia das Construções (20 SPPC), artigo 2SPPC1019, pp. 224-236,

de ensaio das $24 \mathrm{~h}$ para $48 \mathrm{~h}$ e depois decresce ao final do ensaio para leitura menor que a inicial, finalizando em 56,3 $\Omega . m$.

\section{Conclusões}

\subsection{Efeito do grau de saturação}

A medida que o grau de saturação aumentou durante o ensaio de absorção a resistividade nos corpos diminuiram, somente para os cp's com sílica na idade de 28 dias a resistividade em vez de diminuir, teve leve aumento 11,36 para 11,39 $\Omega$.m. Já para o conjunto com 63 e 91 dias a resistividade dos corpos com Sílica diminuiram, enquanto o grau de saturação aumentou, sendo assim, o fator determinante neste caso é o tipo de adição.

$\mathrm{Na}$ condição imersa o grau de saturação aumentou progressivamente em um período de 72 horas durante este tempo os valores de resistividade mantiveram uma tendência a diminuir aos 63 e 91 dias nos três traços. Em estado seco à temperatura ambiente, os valores registrados foram maiores nos três traços.

\subsection{Efeito do grau de hidratação}

Quanto maior o grau de hidratação maior a resistividade do material independentemente do grau de saturação e tipo de adição. Os valores de resistividade aumentaram progressivamente com o aumento da idade dos corpos de prova; os três traços apresentaram igual desempenho. Devido à diminuição da porosidade, oriunda da hidratação do cimento portland.

\subsection{Efeito da resistência}

Quanto maior a resistência maior a resistividade (figura 5). O controle dos níveis de hidratação foi feito de forma indireta através do controle do tempo que os corpos ficaram em condições de cura úmida: 3, 7, 28, 63 e 91 dias. Os resultados de resistência comprovaram que a resistência dos corpos de prova aumentaram em paralelo com o nível de hidratação, assim consequentemente os valores de resistividade também aumentaram, reduzindo as chances de deterioração do concreto.

\subsection{Efeito do tipo de adição}

Os traços com adição de Cinza volante e Sílica de casca de arroz apresentaram maior resistividade do que o traço de referência em todas as idades consideradas. Sendo que a resistividade nos corpos com Cinza volante apresentaram menores valores do que nos corpos com Sílica de casca arroz; desta maneira pode se concluir que quanto mais ativa seja a adição usada maior serão os valores de resistividade e proteção da peça de concreto.

\section{Agradecimentos}

Às empresas Supermix e Itambé, nas pessoas dos engenheiros Maurício Bianchini e Jorge Christófolli, respectivamente, pela doação dos materiais utilizados na pesquisa e auxílio na execução dos ensaios de resistência à compressão. 
OLIVEIRA, I. A.; ET AL.. EFEITO DO GRAU DE HIDRATAÇÃO E DE SATURAÇÃO DO CONCRETO NAS LEITURAS DE RESISTIVIDADE ELÉTRICA. $2^{\circ}$ Simpósio Paranaense de Patologia das Construções (20 SPPC), artigo 2SPPC1019, pp. 224-236,

\section{Referências Bibliográficas}

[1] MEHTA, P.K., "Rice husk ash - A unique supplementary cementing material", In: CANMET, Proceedings of the International Symposium on Advances in Concrete Technology, pp. 407-430, Atens, Greece, May. 1992.

[2] CASCUDO, O. Contribuição ao estudo e emprego de técnicas eletroquímicas no controle da corrosão de armaduras em concreto armado, Dissertação (Mestrado em Engenharia Civil), Escola Politécnica, Universidade de São Paulo, São Paulo, SP, Brasil, 1991.

[3] HELENE, P.R. Contribuição ao estudo da corrosão em armaduras de concreto armado, Tese (Livre Docência), Escola Politécnica, Universidade de São Paulo, São Paulo, SP, Brasil, 1993.

[4] FRIZZO, B.T. Influência do teor e da finura de pozolanas na permeabilidade ao oxigênio na absorção capilar do concreto, Dissertação (Mestrado em Engenharia Civil), Universidade Federal de Santa Maria, Santa Maria, RS, 2001.

[5] SILVA, T.J. "Mecanismos de transporte de massa no concreto", Concreto: Ciência e Tecnologia, IBRACON, v. 1, pp. 809-848, 2011.

[6] ABREU, A.G. Efeito das adições minerais na resistividade elétrica de concretos convencionais, Dissertação (Mestrado em Engenharia Civil), Universidade Federal do Rio Grande do Sul, Porto Alegre, RS, 1998.

[7] MONFORE, G.E. "The electrical resistivity of concrete", Journal of the PCA Research and development Laboratories, pp. 35-49, 1968.

[8] MEDEIROS, M. H. F. Estudo de variáveis que influenciam nas medidas de resistividade de estruturas de concreto armado, Escola Politecnica da Universidade de São Paulo - SP, Brasil, 2001.

[9] BERTOLINI, L. Materiais de construção: patologia, reabilitação, prevenção, pp 257-283, Oficina de textos, São Paulo - Brasil, 2006.

[10] ASTM G-57 Standard test method for field measurement of soil resistivity using the Wenner, Four-electrode method, 2012.

[11] C. ANDRADE, B. ElSENER, C. ALONSO, R. CIGNA,J. GALLAND, J. GULIKERS, U. NÜMBERGER, R. POLDER, V. POLLET, M. SALTA, R. WEIDERT, Corresponding members: C Page, UK; C. Stevenson, Sout; RILEM TC 154-EMC: ELECTROCHEMICALTECHNIQUES FOR MEASURING METALLIC CORROSION, "Test methods for on site measurement of resistivity of concrete"; Materials and Structures, Vol. 33, December2000, pp 603-611 